\title{
Analysis of Zones Created with Waterjet Cutting of AISI 316 L Corrosion Resistant Steel
}

\author{
Miroslav DUSPARA, Valnea STARČEVIĆ, Ivan SAMARDŽIĆ
}

\begin{abstract}
This work deals with the quality of machined surface obtained with waterjet cutting (WJC) technology, regarding the influence of selected dynamic parameters (traverse speed, abrasive mass flow rate and pressure) on the quality of machined surface. Examination presented in the work was carried out on specimens made from AISI 316L corrosion resistant steel and measured with portable surface roughness tester. Results obtained by experiment were analyzed with licensed version of software for statistical analysis Design Expert 10.
\end{abstract}

Keywords: analysis of variance; central composite design; cutting parameters; surface quality; waterjet cutting

\section{INTRODUCTION}

The major target of metal cutting is to ensure high productivity with high quality of product and low machining costs. Type of material and geometry of specimen have the greatest influence on choice of treatment. Those 2 factors usually determine the way of processing, and after the selection of the process, it is necessary to determine operating conditions. The surface finish produced by conventional machining is generally uniform. Therefore, the surface finish of the machined surface simply can be characterized by measuring the surface roughness of any point of machined surface.

However, with waterjet cutting (WJC), the surface finish varies as a function of cutting depth of a specimen. Waterjet cutting is currently considered as one of the most versatile methods of processing that significantly does not depend on properties of material. Despite various advantages over many other conventional processing methods, there are 2 major obstacles limiting its further industrial application: forming of striation marks on machined surface and relatively high machining costs. [1]

\section{RELATED AND PREVIOUS WORK}

Abrasive waterjet removal process is a complex erosion process where more than one mode contributes to the erosion results. Material removal takes place as a result of the erosive action of a large number of impacts (app. $10^{3} / \mathrm{s}$ ) by abrasive particles. [2]

The most pronounced characteristic of a surface machined with waterjet is the development of striation marks, which appear below the smooth and transient zones. The striation marks appear when pressure of waterjet is high and abrasive particles lose a significant amount of energy. The inconsistency in roughness distribution is a unique characteristic of waterjet cutting technology, where surface quality degenerates as the jet approaches the bottom of cut. [3]

In the last three decades material removal process and topography of machined surface represent the prime interest for many researchers. Mohamed Hashish is considered to be a pioneer in the field of material removal process. Based on Bitter's erosive theory, Hashish was one of the first researchers who developed a set of mathematical models to relate the output process variables to waterjet tehnique. Chao et al. evaluated generated surface using surface topography analysis. [4]

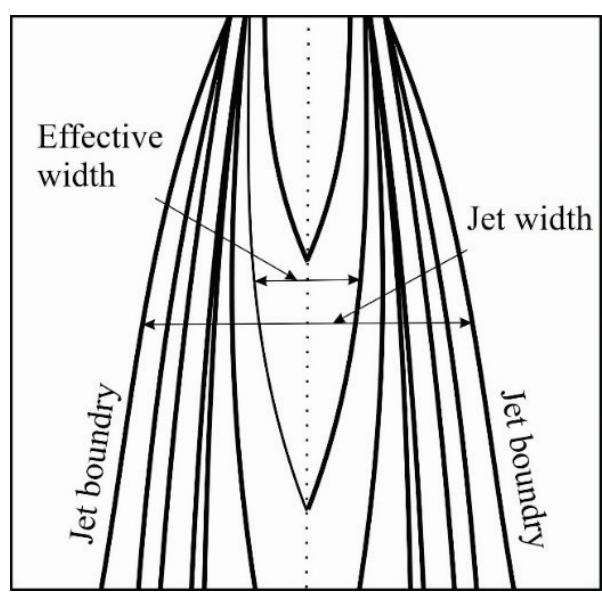

Figure 1 Relative strength zones in waterjet [5]

Few years later, authors Arola and Romulu used regression analysis with the aim of predicting the depth of the cut due to cutting and deformation wear for epoxy and graphite composite materials. [4] Those high velocity motions are used for erosion of workpiece material, where cutting occurs due to collisions of abrasive particles with material that is being cut. For the same reason peripheral particles in jet have lower amount of energy, which eventually creates striation marks. [5, 6]

More recently, the same approach has been employed by Srinivasu and Babu [4] to model and optimize the varying conditions of focusing nozzle in AWJ. Aim of their study was related to the selection of suitable parameters of cutting process which will be able to control the depth of cut within required limits.

Quality of machined surface will depend on effective width (or diameter) of jet, and effective width of jet will depend on jet strength in observed zone (Fig. 1).

\section{EXPERIMENTAL SETUP}

In experimental part of the paper influence of selected cutting parameters was shown on the quality of surface roughness or mathematical model that will, depending on input parameter, predict the quality of machined surface. 
The main goal of the work is qualitative and quantitative prediction of surface roughness of cutting depths $(5,11,19$ and $25 \mathrm{~mm})$ defined in the paper.

The experiments were conducted on TENKING 23020 abrasive waterjet cutting system with ultra high pressure pump capable of providing pressure of water of $400 \mathrm{MPa}$. Cutting was performed on austenitic corrosion resistant steel X2CrNiMo17-12-2 (AISI 316L) of thickness $30 \mathrm{~mm}$ (Tab. 1). In order to achieve more efficient cutting, in water stream were added particles of abrasive material Baron Garnet with mesh No. 80 .

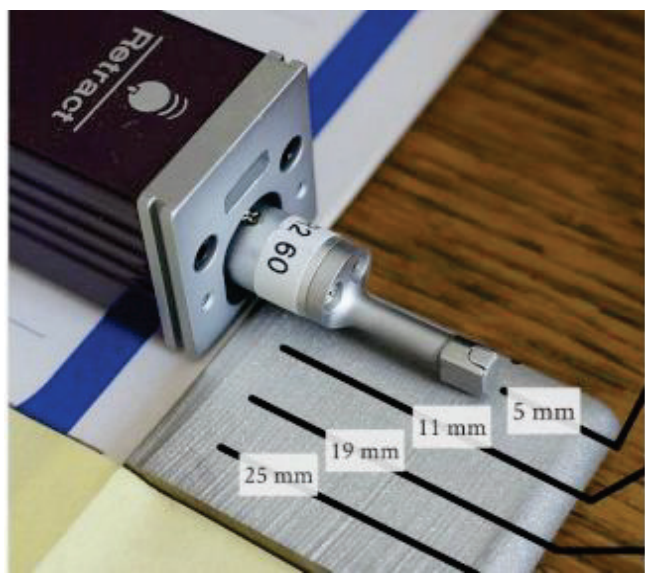

Figure 2 Portable device for 2D measurement of amplitude parameters of surface roughness Mitutoyo SJ 301 Surf Test

Table 1 Chemical compositions of AISI 316L austenitic corrosion resistant steel [7]

\begin{tabular}{|l|c|c|c|c|c|c|c|c|c|}
\hline Steel & $\mathrm{Cr}$ & $\mathrm{Ni}$ & $\mathrm{Mn}$ & $\mathrm{Si}$ & $\mathrm{Mo}$ & $\mathrm{N}$ & $\mathrm{Ti}$ & $\mathrm{Ni}$ & $\mathrm{C}$ \\
\hline AISI316L & $0,16-0,29$ & $0,08-0,36$ & $0,01-0,02$ & $0,005-0,03$ & $<0,02$ & $<0,005$ & $<0,002$ & $<0,002$ & $0,0002-0,0008$ \\
\hline
\end{tabular}

3 independent variables have been selected to analyse their influence on the roughness of machined surface and they varied on 2 levels $(+\alpha$ and $-\alpha)$. The variables include jet traverse speed, pressure of water stream and flow rate of abrasive particles.

The range of variable parameters and their levels are presented in Tab. 2.

Table 2 Variable parameters and their values

\begin{tabular}{|c|c|c|c|c|c|c|c|}
\hline \multirow[b]{2}{*}{ Factors } & \multirow[b]{2}{*}{ Sign } & \multirow[b]{2}{*}{ Unit } & \multicolumn{5}{|c|}{ CODED VALUES OF PARAMETERS } \\
\hline & & & $\begin{array}{c}\text { Low level } \\
(-1)\end{array}$ & $\begin{array}{c}\text { Center level } \\
(0)\end{array}$ & $\begin{array}{l}\text { High level } \\
(+1)\end{array}$ & $\begin{array}{c}-\alpha \\
(-1,682)\end{array}$ & $\begin{array}{c}+\alpha \\
(+1,682)\end{array}$ \\
\hline Jet traverse speed & $v_{\mathrm{f}}$ & $\mathrm{mm} / \mathrm{min}$ & 25 & 30 & 35 & 21,86 & 38,4 \\
\hline Pressure of water jet & $p$ & $\mathrm{MPa}$ & 310 & 325 & 340 & 299.7 & 350,2 \\
\hline Flow rate of abrasive & $m_{\mathrm{a}}$ & $\mathrm{kg} / \mathrm{min}$ & 0,35 & 0,4 & 0,45 & 0,32 & 0,49 \\
\hline
\end{tabular}

From the published literature it was found that waterjet cutting involves a large number of process variables, and virtually all these variables will affect cutting performance. Generally, all involved parameters can be classified into two categories: the input or independent parameters and output or dependent parameters. Among many process variables influencing the cutting results, 3 independent variables were selected which were considered to be the factors within the experimental phase. The implicit function representation is shown in Eq. (1). [8]

$R a=f\left(v_{c}, p, m_{a}\right)$.

\section{DESIGN OF EXPERIMENT (DOE)}

Surface roughness is defined as the inherent irregularities of specimen created during the machining processes. The key indication of the degree of quality of the surface on the machined parts is the surface roughness $R a$, along with the waviness $W_{\mathrm{a}}$, and the mean value of the surface roughness is defined as stated in Eq. (2). [9, $10]$

$R a=\frac{1}{l} \int_{0}^{l}|y(x)| \mathrm{d} x$,

where: $R a$ - arithmetic mean of the absolute values of profile deviations from the mean line of the roughness profile, $l$ - sampling length, $y(x)$ - the ordinate of the profile curve.
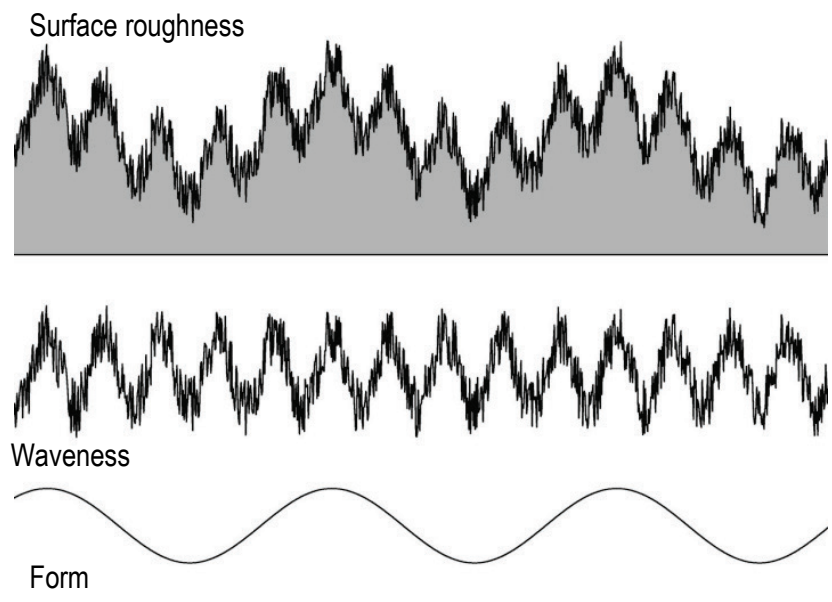

Figure 3 Geometric components of surface roughness [10]

Three topographical components - waveness, roughness and errors of form compose a machined part of surface texture. The irregular nature of a surface arrises from several processing factors. Geometrical components of surface roughness are shown in Fig. 3.

The surface roughness was measured at 4 levels across the thickness of the cut: $5 \mathrm{~mm}, 11 \mathrm{~mm}, 19 \mathrm{~mm}$ and $25 \mathrm{~mm}$ using portable surface roughness test Mitutoyo SurfTest SJ - 301according to ISO standardu 4287 1997. (Fig. 2). 


\section{SURFACE TOPOGRAPHY CHARACTERISTIC}

With a closer look at the surface of specimen machined with AWJC,

On the surface samples made from AISI $316 \mathrm{~L}$ steel 4 different topographical zones can be clearely distinguished: initiation zone, smooth zone, transition and rough zone. Every zone is characterised by characteristic topography and different values of surface parameters $R a$, $R q$ and $R z$. [11]

Initiation zone represents a very narrow area (appr. 2 $\mathrm{mm}$ ) at the beginning of entry zone and represents the place where material achieves its first contact with water jet. Initiation zone has a bit darker colour of surface, and relatively high values of surface parameters $R a, R q$ and $R z$. [12]

Smooth zone is characterised by uniform structure, difference between values of surface roughness is quite small (asumed value is in the range of 2-3 $\mu \mathrm{m}$ ). Transition zone represents a place where striations (wavy structure) start to form on the surface. This zone is located between smooth and rough zone and consists of the characteristics of both. Values of surface at the beginning of zone are slightly elevated compared to smooth zone $(\approx 3.8 \mu \mathrm{m})$ and with the increase of depth of cut surface quality deteriorates.

Approximately at the middle of zone striation marks are starting to form at the surface of material and are further spreading as the jet moves. Rough zone represents the place on material where waterjet exits from material. Surface of the mentioned zone is almost covered with deeper and lower striations, poor quality of machined surface and large disipation of surface roughness values.

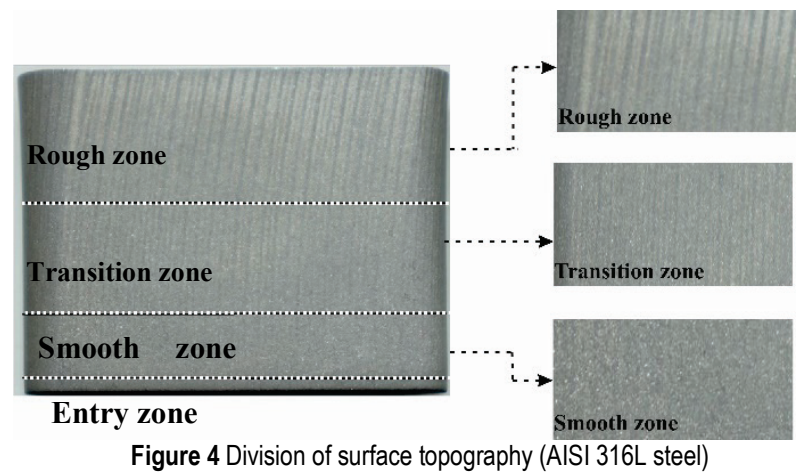

\section{MODELLING DEVELOPMENT}

In order to obtain the independant and higher order effects of different process variables on values of surface roughness, experiment was performed using central composite design (CCD). The adequacy of the selected model for every level of cutting was tested using analysis of variance. [9]

Table 3 DOE matrix and values of surface roughness for all levels

\begin{tabular}{|c|c|c|c|c|c|c|c|c|}
\hline \multirow[b]{2}{*}{ Run } & \multirow{2}{*}{$\begin{array}{l}\text { Status label of } \\
\text { the experiment }\end{array}$} & \multicolumn{3}{|c|}{ PROCESS FACTORS } & \multicolumn{4}{|c|}{ SURFACE ROUGHNESS Ra } \\
\hline & & $\begin{array}{c}\text { Pressure of water } \\
\text { jet / } \mathrm{MPa}\end{array}$ & $\begin{array}{c}\text { Jet traverse speed / } \\
\mathrm{mm} / \mathrm{min}\end{array}$ & $\begin{array}{c}\text { Flow rate } \\
\mathrm{kg} / \mathrm{min}\end{array}$ & $\begin{array}{c}\text { Zone at } \\
5 \mathrm{~mm}\end{array}$ & $\begin{array}{l}\text { Zone at } \\
11 \mathrm{~mm}\end{array}$ & $\begin{array}{c}\text { Zone at } 19 \\
\mathrm{~mm}\end{array}$ & $\begin{array}{c}\text { Zone at } 25 \\
\mathrm{~mm}\end{array}$ \\
\hline 1 & 1 & 340 & 35,00 & 0,45 & 2,92 & 3,83 & 6,47 & 9,19 \\
\hline 2 & 2 & 310 & 25,00 & 0,45 & 2,87 & 3,74 & 5,33 & 6,44 \\
\hline 3 & 3 & 340 & 25,00 & 0,45 & 2,67 & 3,18 & 5,17 & 6,34 \\
\hline 4 & 4 & 325 & 30,00 & 0,40 & 3,02 & 3,6 & 5,97 & 7,80 \\
\hline 5 & 5 & 310 & 25,00 & 0,35 & 2,86 & 3,79 & 6,13 & 7,92 \\
\hline 6 & 6 & 325 & 30,00 & 0,40 & 3,06 & 3,65 & 6,10 & 7,40 \\
\hline 7 & 7 & 325 & 30,00 & 0,32 & 2,83 & 4,43 & 6,70 & 12,57 \\
\hline 8 & 8 & 325 & 30,00 & 0,40 & 2,95 & 3,8 & 5,86 & 7,00 \\
\hline 9 & 9 & 325 & 30,00 & 0,48 & 2,77 & 3,71 & 5,92 & 6,78 \\
\hline 10 & 10 & 310 & 35,00 & 0,35 & 3,48 & 4,81 & 7,48 & 13,87 \\
\hline 11 & 11 & 340 & 25,00 & 0,35 & 2,45 & 3,54 & 5,99 & 7,02 \\
\hline 12 & 12 & 300 & 30,00 & 0,40 & 3,28 & 4,64 & 6,93 & 10,75 \\
\hline 13 & 13 & 325 & 38,40 & 0,40 & 3,25 & 4,93 & 7,88 & 14,77 \\
\hline 14 & 14 & 340 & 35,00 & 0,35 & 3,13 & 4,67 & 7,31 & 12,97 \\
\hline 15 & 15 & 350 & 30,00 & 0,40 & 2,92 & 3,7 & 5,98 & 7,6 \\
\hline 16 & 16 & 310 & 35,00 & 0,45 & 2,94 & 4,38 & 7,37 & 13,46 \\
\hline 17 & 17 & 325 & 21,60 & 0,40 & 2,49 & 3,2 & 5,44 & 4,93 \\
\hline 18 & 18 & 325 & 30,00 & 0,40 & 2,95 & 3,5 & 6,00 & 7,89 \\
\hline
\end{tabular}

Values of surface roughness for all levels were analysed with statistical software package Design Expert Version10. The design of experiment was $2^{3}$ factorial with 4 central points, which requires 18 test runs per level (total 72 test runs). The design matrix (number of experiments and order of run) with surface roughness model as a response is shown in Tab. 3 .

First step in statistical analysis is to determine wheather there is a need for transformation of data. Based on response range of data in experiment which is less than 10 (1.42), software suggests that there is no need for transformation of data. Next step represents the selection of adequate regression model for each cutting zone.
Best model is the most fitted function to the experimental data. In this paper, checking the model adequacy is conducted with the analysis of variance (ANOVA) tehnique. Models were tested in relation to the mean square deviations, deviations from model and determination coefficients. [9]

Results obtained by ANOVA recommended that the quadratic regression model is statistically the best fit for all cutting zones. $P$ - value for all zones obtained by conducted statistical analysis showed that value of models is lower than 0.05, which indicates that models are statistically significant. With backward elimination based on $p$ - values, all insignificant terms are eliminated in order to adjust the fitted model. [9] 
Analysis of variance for regression model $R a_{5}$ is shown in Tab. 4.

Table 4 Analysis of variance for regression model $R a_{5}$

\begin{tabular}{|l|c|c|c|c|c|}
\hline \multicolumn{1}{|c|}{ Symbol } & S.S & dof & M.S. & $F$ - value & $p$ - value \\
\hline Model & 150,2 & 6 & 25,04 & 29,70 & $<10^{-4}$ \\
\hline A:pressure & 9,63 & 1 & 9,63 & 11,42 & 0,0061 \\
\hline $\begin{array}{l}\text { B:traverse } \\
\text { speed }\end{array}$ & 107,5 & 1 & 107,5 & 127,54 & $<10^{-4}$ \\
\hline C: flow rate & 18,95 & 1 & 18,95 & 22,48 & $6 \times 10^{-4}$ \\
\hline $\mathrm{A}^{2}$ & 4,19 & 1 & 4,19 & 4,97 & 0,0475 \\
\hline $\mathrm{B}^{2}$ & 8,39 & 1 & 8,39 & 9,95 & 0,0786 \\
\hline $\mathrm{C}^{2}$ & 7,16 & 1 & 7,16 & 8,50 & 0,0092 \\
\hline Residuals & 9,27 & 11 & 0,84 & - & 0,0141 \\
\hline Lack of fit & 8,77 & 8 & 1,10 & 6,58 & 0,0745 \\
\hline Pure error & 0,5 & 3 & 0,17 & - & - \\
\hline Total & 159,5 & 17 & - & - & - \\
\hline
\end{tabular}

Table 5 Analysis of variance for regression model $R a_{11}$

\begin{tabular}{|l|c|c|c|c|c|}
\hline \multicolumn{1}{|c|}{ Symbol } & S.S & $d o f$ & M.S. & $F$ - value & $p$-value \\
\hline Model & 4,76 & 6 & 0,79 & 27,33 & $<10^{-4}$ \\
\hline A :pressure & 0,70 & 1 & 0,70 & 23,97 & $5 \times 10^{-4}$ \\
\hline $\begin{array}{l}\text { B : traverse } \\
\text { speed }\end{array}$ & 2,95 & 1 & 2,95 & 101,80 & $<10^{-4}$ \\
\hline C:flow rate & 0,61 & 1 & 0,61 & 21,10 & $8 \times 10^{-4}$ \\
\hline $\mathrm{A}^{2}$ & 0,32 & 1 & 0,32 & 10,96 & 0,006 \\
\hline $\mathrm{B}^{2}$ & 0,19 & 1 & 0,19 & 6,43 & 0,027 \\
\hline $\mathrm{C}^{2}$ & 0,19 & 1 & 0,19 & 6,62 & 0,025 \\
\hline Residuals & 0,32 & 11 & 0,029 & - & - \\
\hline Lack of fit & 0,27 & 8 & 0,034 & 2,18 & 0,2818 \\
\hline Pure error & 0,047 & 3 & 0,016 & - & - \\
\hline Total & 5,07 & 17 & - & - & - \\
\hline
\end{tabular}

Table 6 Analysis of variance for regression model $R a_{19}$

\begin{tabular}{|l|c|c|c|c|c|}
\hline \multicolumn{1}{|c|}{ Symbol } & S.S & $d o f$ & M.S. & $F$ - value & $p$ - value \\
\hline Model & 9,87 & 5 & 1,97 & 46,80 & $<10^{-4}$ \\
\hline A:pressure & 0,64 & 1 & 0,64 & 15,28 & 0,0021 \\
\hline $\begin{array}{l}\text { B: traverse } \\
\text { speed }\end{array}$ & 7,49 & 1 & 7,49 & 177,51 & $<10^{-4}$ \\
\hline C:flow rate & 1,10 & 1 & 1,10 & 26,15 & 0,0003 \\
\hline $\mathrm{A}^{2}$ & 0,21 & 1 & 0,21 & 4,97 & 0,0456 \\
\hline $\mathrm{B}^{2}$ & 0,52 & 1 & 0,52 & 12,34 & 0,0043 \\
\hline Residuals & 0,51 & 12 & 0,042 & - & - \\
\hline Lack of fit & 0,48 & 9 & 0,053 & 5,43 & 0,0955 \\
\hline Pure error & 0,02 & 3 & $9,8 \cdot 10^{-4}$ & - & - \\
\hline Total & 10,38 & 17 & - & - & - \\
\hline
\end{tabular}

Table 7 Analysis of variance for regression model $R a_{25}$

\begin{tabular}{|l|c|c|c|c|c|}
\hline \multicolumn{1}{|c|}{ Symbol } & S.S & $d o f$ & M.S. & $F$ - value & $p$ - value \\
\hline Model & 150,2 & 6 & 25,04 & 29,70 & $<10^{-4}$ \\
\hline A : pressure & 9,63 & 1 & 9,63 & 11,42 & 0,0061 \\
\hline $\begin{array}{l}\text { B:traverse } \\
\text { speed }\end{array}$ & 107,5 & 1 & 107,52 & 127,54 & $<10^{-4}$ \\
\hline C : flow rate & 18,95 & 1 & 18,95 & 22,48 & 0,0006 \\
\hline $\mathrm{A}^{2}$ & 4,19 & 1 & 4,19 & 4,97 & 0,0475 \\
\hline $\mathrm{B}^{2}$ & 8,39 & 1 & 8,39 & 9,95 & 0,0092 \\
\hline $\mathrm{C}^{2}$ & 7,16 & 1 & 7,16 & 8,50 & 0,0141 \\
\hline Residuals & 9,27 & 11 & 0,84 & - & - \\
\hline Lack of fit & 8,77 & 8 & 1,10 & 6,58 & 0,0745 \\
\hline Pure error & 0,50 & 3 & 0,17 & - & - \\
\hline Total & 159,5 & 17 & & - & - \\
\hline
\end{tabular}

Analysis of variance for regression model $R a_{11}$ is shown in Tab. 5.

Analysis of variance for regression model $R a_{19}$ is shown in Tab. 6.

Analysis of variance for regression model $R a_{25}$ is shown in Tab. 7.

Analysis of variance for Tab. 5 - 7 shows that model is significant. Jet traverse speed represents dominant model term in all four regression models, but effect of other 2 cutting parameters is not equal for all zones experimented in this paper. Reason for this is because increase of traverse speed has a large effect on the required energy for material removal deriving from a reduction in jet exposure time.

From the tables 4 - 7 it can be concluded that the significant factors influencing surface quality for regression models $R a_{5}$ and $R a_{11}$ are traverse speed and pressure, and for regression models $R a_{19}$ and $R a_{25}$ significant factors are traverse speed and mass flow rate.

As stated by Shanmugan et al. increase in the traverse speed may be associated with a decrease in the jet interaction on a given area of material, which leads to material erosion by fewer abrasive particles and lower surface quality $[13,15,16]$.

\section{OBTAINED RESULTS DURING THE EXPERIMENT}

Following the model simplification process, final forms of predictive models for surface roughness (in terms of analysed parameters) were given as the following expressions:

Surface roughness of regression model $R a_{5}$ :

$R a_{5}=21,35339-0,01849 \cdot p+0,34658 \cdot v_{\mathrm{f}}+6,87861$. $m_{\mathrm{a}}+9,000 E-003 p \cdot m_{\mathrm{a}}-0,490 \cdot v_{\mathrm{f}} \cdot m_{\mathrm{a}}+1,61156 E-$ $006 \cdot p^{2}-1,80229 E-003 \cdot v_{\mathrm{f}}^{2}-27,92239 m_{\mathrm{a}}{ }^{2}$

Surface roughness of regression model $R a_{11}$ :

$R a_{11}=94,11297-0,047303 \cdot p-0,19840 \cdot v_{\mathrm{f}}-43,65078$ $\cdot m_{\mathrm{a}}+7,04596 E-006 \cdot p^{2}+4,85644 E-003 \cdot v_{\mathrm{f}}^{2}+$ $49,27146 \cdot m_{\mathrm{a}}^{2}$

Surface roughness of regression model $R a_{19}$ : $R a_{19}=74,8839-0,037826 \cdot p-0,32805 \cdot v_{\mathrm{f}}-5,68476$. $m_{\mathrm{a}}+5,5965 E-006 \cdot p^{2}+7,93604 E-003 \cdot v_{\mathrm{f}}^{2}$

Surface roughness of regression model $R a_{25}$ :

$R a_{25}=366,04817-0,17191 \cdot p-1,39330 \cdot v_{\mathrm{f}}-$ $264,35629 \cdot m_{\mathrm{a}}+2,55872 E-005 \cdot p^{2}+0,032574 \cdot v_{\mathrm{f}}^{2}+$ $300,99572 \cdot m_{\mathrm{a}}{ }^{2}$

Expected values of responses also can be displayed in graphical form, for all experimental area, which represents the place of potential combination of parameters. The response surface for surface roughness $(R a)$ for all cutting zones was obtained for the interaction terms in the reduced quadratic model (Fig. 5 - 8).

But, with the increase of feed rate machined surface deteriorates. This is due to the fact that as the work moves faster, smaller number of particles is available that pass through a unit area. Therefore, smaller number of impacts and cutting edges is available per unit area, which results in a rougher surface. $[9,16]$

Influence of pressure of water stream on quality of machined surface is also important: as the pressure of stream increases, surface of machined material becomes smoother. Due to increase in jet pressure, the kinetic energy of the particles increases which results in smoother machined surface. $[17,18,19]$

From the selected cutting parameters, jet traverse speed represents the parameter with the largest influence on quality of machined surface. In order to reduce costs of machining, many users are chosing as hard as possible feed rate of cutting head. 


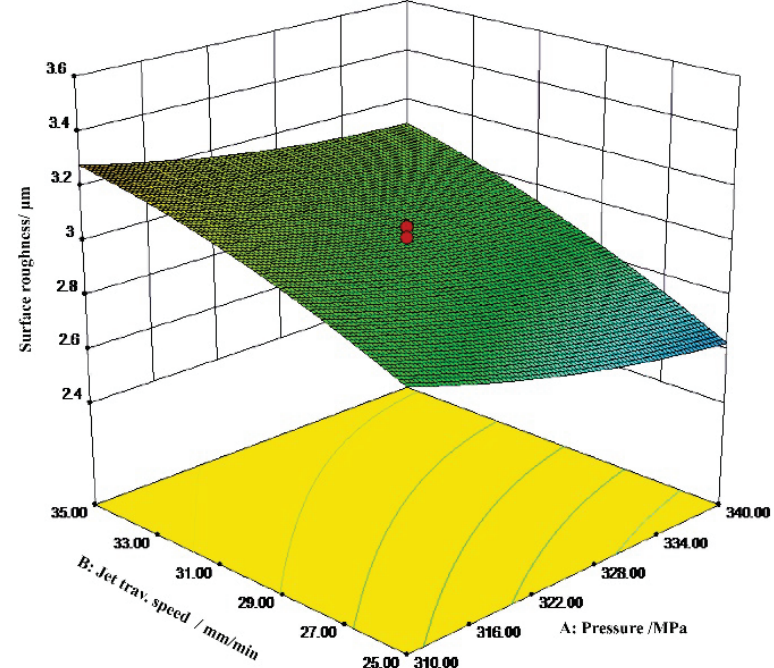

Figure 5 Plots of estimated variance for regression model $R a_{5}$ with mass flow rate $m_{\mathrm{a}}=0,4 \mathrm{~kg} / \mathrm{min}$

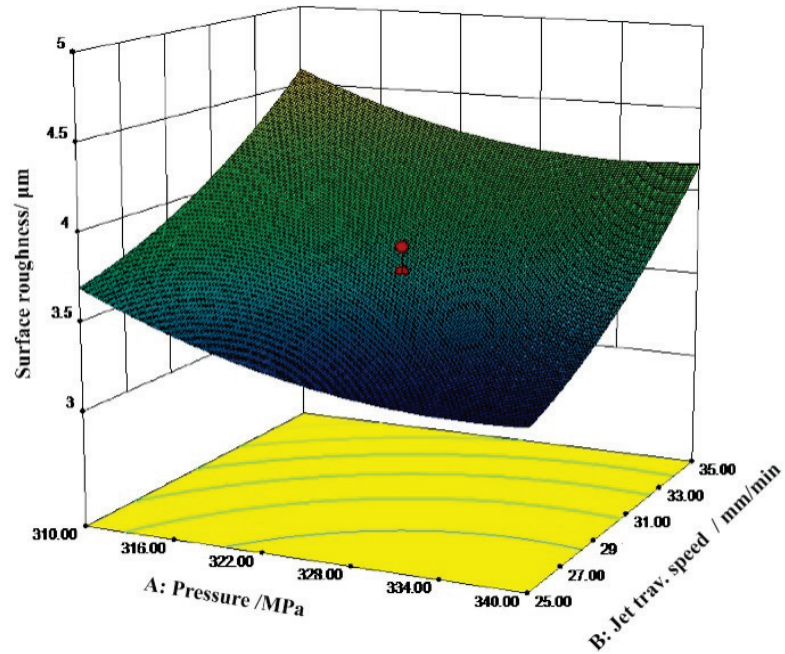

Figure 6 Plots of estimated variance for regression model $R a_{11}$ with constan mass flow rate $m_{\mathrm{a}}=0,4 \mathrm{~kg} / \mathrm{min}$

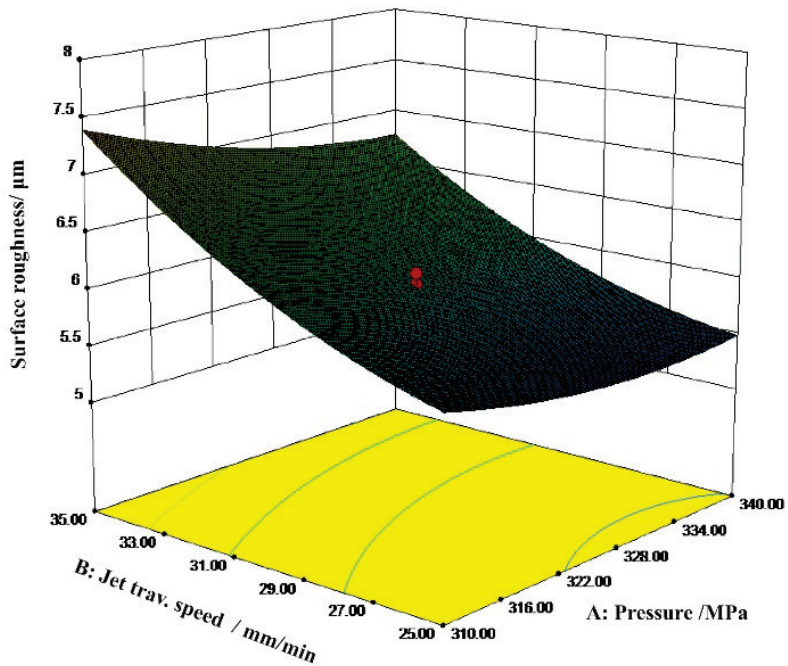

Figure 7 Plots of estimated variance for regression model $R a_{19}$ with constant mass flow rate $m_{\mathrm{a}}=0,4 \mathrm{~kg} / \mathrm{min}$

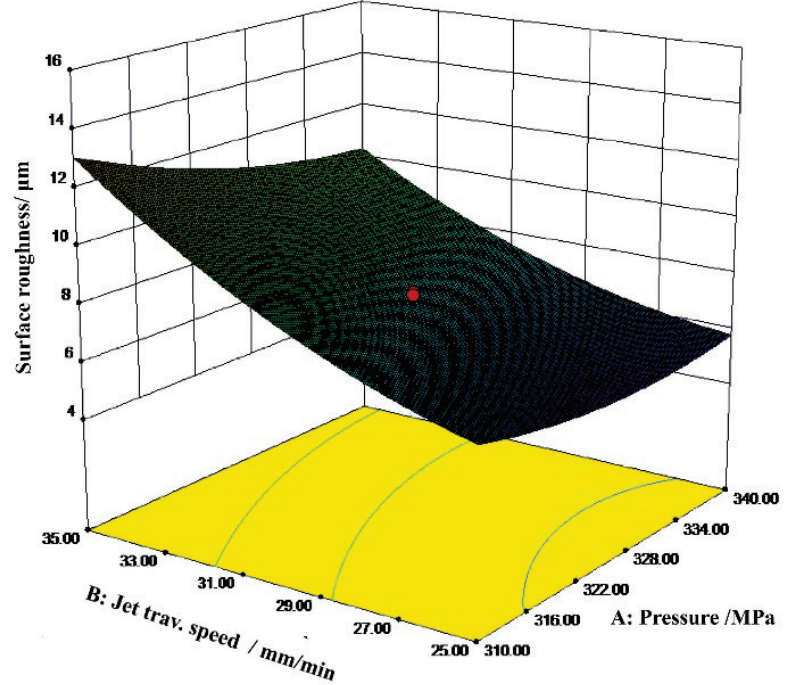

Figure 8 Plots of estimated variance for regression model $R a_{25}$ with constant mass flow rate $m_{\mathrm{a}}=0,4 \mathrm{~kg} / \mathrm{min}$

Mass flow rate of abrasive particles did not show prominent influence on quality of machined surface (i.e. not significant cutting parameter). Although, with the addition of abrasive particles cutting power and ability of water stream increase, quality of machined surface decreases when amount of abrasive particles in stream increases. Abrasive particles in water stream collide among themselves and that results in loosing of kinetic energy and poor quality of machined surface. $[18,20]$

From Fig. 3 can be spotted that the quality of machined surface is greatest at the place where jet penetrates into the material (top surface), and increasingly becomes rougher and rougher as the jet aproaches to the end of material (bottom surface). Explanation for that phenomenon is simple: as the particles move down, they lose their kinetic energy and their cutting ability deteriorates. $[9,18,19,20]$

\section{CONCLUSION}

In this paper, influence of process parameters of surface machined by abrasive waterjet cutting has been examined. Experiments were conducted on specimens made from steel AISI 3161 with variation of 3 selected cutting parameters on 2 levels.

Statistical regression analysis has been employed to develop mathematical models for 4 different cutting depth relating process parameters: jet traverse speed, mass flow rate and pressure of water stream to the surface roughness. From the experimental part of the paper conclusions can be made:

- The surface of specimen being cut with abrasive waterjet can be characterised by 4 types of surface texture: initiation zone, smooth zone, transition and rough zone.

- As expected, ANOVA has proved that jet traverse speed has the largest influence on the quality of machined surface. In order to reduce the cost of the machining process many users choose the speed as high as possible, but increasing of speed is related to deterioration of surface and poor quality of machined surface. 
- Striation marks on surface of material are disadvantages which represent limitation for further application of AWJC in production facilities. Mechanism of forming striations is still not fully explnained.

- The abrasive mass flow rate is considered not a significant machining parameter during the AWJ cutting method.

- Also, if we are trying to reduce production costs, the amount of abrasive particles is reduced according to the recomendation of manufacturer, since the $R a$ to some degree changes by increasing the abrasive mass flow rate.

- This means that a low value of the traverse rate should be used to obtain higher smoothness of the machined surface but then again this is at the cost of sacrificing productivity.

- Low values of surface roughness will require a higher number of abrasive particles per unit area. Mentioned combination of parameters will result from a lower feed rate. The solution is selection of medium value of the feed rate which can be achieved greater efficiency with tolerable machined surface texture quality.

\section{REFERENCES}

[1] Burama, C. D. \& Kim, T. J. (1989). Statistic characterization of surface finish produced by a high pressure abrasive waterjet. Proceeding of the $5^{\text {th }}$ American Waterjet Conference / Toronto, Canada, 165-175.

[2] Hassan, A. I. \& Kosmol, J. (1997). An overview of abrasive waterjet machining (AWJM) https://www.academia.edu/ 12087162/an overview of abrasive waterjet machining AWJM (08.07.2016)

[3] Hloch, S., Stoić, A., Kozak, D., Samardžić, I., Novak Marcinčin, J., \& Modrak, V. (2011). Rezanje mlazom vode, 1. izdanje, Slavonski Brod, Strojarski fakultet u Slavonskom Brodu, 118 - 122.

[4] Kolahan, F. \& Kolahan, K. A. (2009). Modeling and Optimization of Abrasive Waterjet Parameters using Regression Analysis. World Academy of Science, Engineering and Technology, 35, 448-493.

[5] Wang, J. (1999). Abrasive Waterjet Machining of Polymer Matrix Composites - Cutting Performance, Erosive Process and Predictive Models. The International Journal of Advanced Manufacturing Technology, 15(10), 757-768. https://doi.org/10.1007/s001700050129

[6] Arola, D. \& Romulu, M. (1996). A study of kerf characteristics in abrasive waterjet machining of graphite/ epoxy composition. Transactions of ASME, Journal of Engineering Materials and Technology, 117(2), 259-261,

[7] Fakultet strojarstva i brodogradnje u Zagrebu, Austenitni nehrđajući čelici. http://www.fsb.unizg.hr/usb_frontend/ files/1354629739-0-ssnc 7i8 pred tekst.pdf (08.06.2016)

[8] Monková, K., Monka, P., Čep, R., Müllerova, J., Bražina, D., \& Duspara, M. (2011). Factor analysis of abrasive waterjet factors affecting the surface roughness of titanium. Technical Gazzete, 18(1), 73-77.

[9] Alsoufi, A. M et al. (2007). Influence of Abrasive Waterjet Machining Parameters on the Surface Texture Quality of Carrara Marble. Journal of Surface Engineered Materials and Advanced Technology, 7, 25-37. https://doi.org/10.4236/jsemat.2017.72003

[10] Jiang, X. et al. (2007). Paradigm shift of surface metrology. Part 1. Historical philosophy. Proceedings of Royal Society A, 463, 2049-2070. https://doi.org/10.1098/rspa.2007.1874

[11] Hloch, S. \& Valiček, J. (2009). Topography of entry zone surfaces created by Hydroabrasive Cutting. International Scientific Journal of Scientific Tehnical Union of Mechanical Engineering, 11-12, 21-24.

http://www.mech-ing.com/journal/Archive/2009/1112/II_TEHNOLOGII/32 MTM_Hloch,Valicek_iniciacna\% 20zona.pdf (16.05.2017)

[12] Brilova, K. et al. (2012). Spectral Analysis of Metallic Surfaces Topography generated by Abrasive Waterjet. Tehnical Gazzete, 19(1), 1-9.

[13] Xu, S. (2005). Modeling in Cutting Process and Cutting Performanse in Abrasive Waterjet Machining with Controled Nozzle Oscilation, Scool of Engeneering Systems, Queensland University of Technology, Queensland, Ph.D. thesis, 235-238.

[14] Zeung, J. \& Kim, T. J. (1992). Development of an abrasive waterjet kerf cutting model for brittle materials. $11^{\text {th }}$ International Conference on Jet Cutting Technology / Bedford, UK, 186-174. https://doi.org/10.1007/978-94-011-2678-6_33

[15] Sharma, A. \& Lalwani, D. (2013). Experimental investigation of process parameters influence on surface roughness in abrasive waterjet machining of AISI H13 die steel; MechanicalEngineering department. Proceedings to Conference on Intelligent Robot, Automation and Manufacturing / Indor, India, 333-341.

[16] Karakurt, I., Aydin, G., \& Kerim, A. (2011). Analysis of the kerf angle of the granite machined by abrasive waterjet (AWJ). Indian Journal of Engineering \& Material Science $18,435-442$.

[17] Glogović, Z. (2010). Utjecaj parametara plinskog naštrcavanja na svojstva nanešenog sloja, Zagreb, Faculty of Mechanical Engineering and Naval Architecture, University of Zagreb, Ph.D. theesis, 212-213.

[18] Gyliene, V. et al. (2014). Investigation of abrasive waterjet cutting parameters influence on 6082 alluminium alloy surface roughness. Mechanika, 20(6), 602-606.

[19] Kovacevic, R. (1991). Surface texture in Abrasive Waterjet cutting. Journal of Manufacturing Systems, 10(1), 32- 39. https://doi.org/10.1016/0278-6125(91)90045-4

[20] Chitrirai pon Selvan, M. et al. (2012). Effects of process parameters on surface roughness in abrasive waterjet cutting of aluminium. Frontiers of Mechanical Engineering, 7, 439-444. https://doi.org/10.1007/s11465-012-0337-0

\section{Contact information}

Miroslav DUSPARA, dr. sc.

Faculty of Mechanical Engineering, J. J. Strossmayera University of Osijek, Trg Ivane Brlić Mažuranić 2, 35000 Slavonski Brod, Croatia E-mail: Miroslav.Duspara@sfsb.hr

Valnea STARČEVIĆ, mag. ing. mech.

Faculty of Mechanical Engineering, J. J. Strossmayera University of Osijek, Trg Ivane Brlić Mažuranić 2, 35000 Slavonski Brod, Croatia

E-mail: vstarcevic@sfsb.hr

Ivan SAMARDŽıć, prof. dr. sc.

Faculty of Mechanical Engineering, J. J. Strossmayera University of Osijek, Trg Ivane Brlić Mažuranić 2, 35000 Slavonski Brod, Croatia E-mail: Ivan.Samardzic@sfsb.hr 